\title{
Direct Measurement of AMPA Receptor Desensitization Induced by Glutamatergic Synaptic Transmission
}

\author{
Thomas Otis, Su Zhang, and Laurence O. Trussell \\ Department of Neurophysiology, University of Wisconsin, Madison, Wisconsin 53706
}

\begin{abstract}
Although almost all ionotropic neurotransmitter receptors undergo desensitization, the onset and recovery of desensitization at a synapse have never been observed directly. We have found changes in postsynaptic AMPA receptor sensitivity in neurons of the chick cochlear nucleus, the nucleus magnocellularis (nMAG), by photolysis of caged glutamate immediately after activation of a single synaptic input. Additionally, synaptic desensitization was demonstrated via competition between synaptically released glutamate and an exogenous nondesensitizing agonist, kainate. Both approaches indicated that at least $35-40 \%$ of the receptors were desensitized after a single synaptic stimulus. Miniature synaptic currents were depressed
\end{abstract}

after an evoked synaptic current, indicating that desensitization led to a reduction in the response to individual transmitter quanta. Stimulation of adjacent glutamatergic inputs to the same cell demonstrated that nearby terminals did not depress one another, suggesting that the desensitizing level of glutamate is restricted to each axon terminal. These findings confirm that postsynaptic neurons may use desensitization to regulate the strength of transmission on a synapse-specific basis.

Key words: glutamate receptors; kainate; AMPA; desensitization; synaptic transmission; voltage clamp; caged compounds; auditory; brain slice
As first shown by Kiskin et al. (1986), AMPA receptors in vertebrate neurons undergo rapid desensitization with sudden exposure to glutamate. The striking speed of this process led to the proposal that such desensitization might occur physiologically to regulate the size and shape of synaptic currents (Dudel et al., 1988; Trussell et al., 1988; Tang et al., 1989; Trussell and Fischbach, 1989). One line of evidence suggesting that synaptic activity leads to desensitization is the similarity in the rate of synaptic current decay and receptor desensitization, although this relation holds only for certain neuronal cell types (Trussell and Fischbach, 1989; Livsey et al., 1993; Otis et al., 1996). In apparent agreement, drugs that interfere with the onset of desensitization slow the decay of glutamatergic synaptic currents and reduce synaptic depression (Isaacson and Nicoll, 1991; Tang et al., 1991; Vyklicky et al., 1991; Trussell et al., 1993; Yamada and Tang, 1993). However, these drugs may have diverse, even presynaptic, sites of action (Patneau et al., 1993; Diamond and Jahr, 1995). Thus, despite correlative data, there is no direct evidence that glutamate released from a synapse reduces the sensitivity of the postsynaptic receptors.

At the calyceal synapse formed by auditory nerve fibers on neurons of the avian nMAG, the neurotransmitter glutamate activates postsynaptic AMPA receptors, generating a large, stimulus-evoked excitatory postsynaptic current (eEPSC; Zhou and Parks, 1992; Zhang and Trussell, 1994a). Several indirect lines of evidence suggest that synaptically released glutamate induces

\footnotetext{
Received Aug. 2, 1996; revised Sept. 11, 1996; accepted Sept. 13, 1996.

This work was supported by National Institutes of Health Grants NS28901 to L.T. and GM16300 to T.O. We thank Drs. Steve Kriegler, Indira Raman, and Margaret Rathouz for helpful comments.

Correspondence should be addressed to Dr. L. Trussell, Department of Neurophysiology, University of Wisconsin, Madison, WI 53706.

Dr. Otis's present address: The Vollum Institute, L474, 3181 SW Sam Jackson Park Road, Portland, OR 97201.

Dr. Zhang's present address: Howard Hughes Medical Institute, Department of Neuroscience, Johns Hopkins University, PCTB 930, 750 North Wolfe Street, Baltimore, MD 21205.

Copyright (C) 1996 Society for Neuroscience $0270-6474 / 96 / 167496-09 \$ 05.00 / 0$
}

AMPA receptor desensitization at this synapse. Pairs of evoked eEPSCs elicited within tens of milliseconds exhibit strong synaptic depression that recovers over tens of milliseconds (Trussell et al., 1993). Computational models of transmitter diffusion predict that the decline in glutamate concentration in this synapse is biphasic, with a rapid $(500 \mu \mathrm{sec})$ decline from millimolar levels and a much slower removal (up to tens of milliseconds) of micromolar levels after release (Otis et al., 1996). Because AMPA receptors are desensitized by only micromolar concentrations of glutamate (Kiskin et al., 1986; Trussell and Fischbach, 1989; Colquhoun et al., 1992), desensitization possibly could underlie synaptic depression. If this were true, the slow phase of glutamate clearance would influence the rate of recovery from depression. We directly tested for desensitization in the present study with whole-cell recording techniques on nucleus magnocellularis (nMAG) neurons in brainstem slices in which receptor sensitivity was assayed immediately after the eEPSC, and we show that significant receptor desensitization can occur during synaptic transmission.

\section{MATERIALS AND METHODS}

Recordings. Brainstem slices (200-300 $\mu \mathrm{m})$ were prepared from embryonic chicks (E17-21) as described previously (Zhang and Trussell, 1994a; Otis et al., 1996). The slices were stored in and, during recordings, perfused with an oxygenated extracellular solution $\left(22-24^{\circ} \mathrm{C}\right)$ composed of (in mM): $140 \mathrm{NaCl}, 20$ glucose, $10 \mathrm{HEPES}, 5 \mathrm{KCl}, 3 \mathrm{CaCl}_{2}$, and 1 $\mathrm{MgCl}_{2}$. For all $\mathrm{Sr}^{2+}$ experiments, $2 \mathrm{mM} \mathrm{SrCl}_{2}$ was added to the standard extracellular solution; in zero $\mathrm{Ca}^{2+}$ solutions, $\mathrm{MgCl}_{2}$ was substituted for $\mathrm{CaCl}_{2}$. Slices were bathed in antagonists of NMDA, $\mathrm{GABA}_{\mathrm{A}}$, and glycine receptors $(100 \mu \mathrm{M}$ D,L 2-amino-5-phosphonovalerate, $5 \mu \mathrm{M}$ SR-95531, and $2 \mu \mathrm{M}$ strychnine, respectively) to isolate AMPA receptor-mediated eEPSCs and miniature excitatory postsynaptic currents (mEPSCs). Recording pipettes contained (in mM): $70 \mathrm{Cs}_{2} \mathrm{SO}_{4}, 40$ TEA-Cl, 10 HEPES, 5 BAPTA, $4 \mathrm{NaCl}$, and $1 \mathrm{MgCl}_{2}$. Pipette resistance in whole-cell configuration (mean $4.8 \pm 2.8 \mathrm{M} \Omega ; n=37$ cells) was compensated by $80-90 \%$, leaving an average uncompensated series resistance of $<1 \mathrm{M} \Omega$. eEPSCs were elicited $(0.08-0.033 \mathrm{~Hz} ; 100-200 \mu \mathrm{sec} / 10-100 \mathrm{~V}$ stimuli) with an extracellular glass pipette. Zhang and Trussell (1994b) discussed evidence that this method of stimulation activates a single axonal input. Briefly, the synaptic response is stable on increase in the stimulus strength by at least 
$5 \mathrm{~V}$ above threshold, and the response is lost with movement of the stimulus pipette by only a few micrometers. Most significantly, when two stimulus pipettes are used, as in the experiments presented here, it is possible to demonstrate independent stimulation of two synapses to the same cell (see below).

Signals from an Axopatch 200A (Axon Instruments, Foster City, CA) were stored on videotape and later filtered $(3 \mathrm{kHz})$, digitized $(10 \mathrm{kHz})$, and analyzed by Strathclyde Software (Dr. J. Dempster, University of Strathclyde, UK) for mEPSC analysis or pCLAMP software (Axon Instruments) for evoked EPSCs. Miniature EPSCs were detected if they exceeded an amplitude ( -2.5 to $-3 \mathrm{pA})$ threshold for $300-400 \mu \mathrm{sec}$; spurious detected events were excluded by eye.

Uncaging glutamate. A $100 \mathrm{~W} \mathrm{Hg}$ lamp was mounted to the epifluorescence port of a Zeiss Axioskop and shuttered (Uniblitz, Vincent Associates, Rochester, NY) under computer control. With the shutter open, the lamp provided full-field illumination, focused by the quartz-reflected light insert, dichroic mirror, and $63 \times$ water immersion objective (Zeiss, 0.9 numerical aperture). The DIC analyzer was removed from the optical path. $\gamma$-CNB-glutamic acid [ $\gamma$ - $(\alpha$-carboxy-2-nitrobenzyl $)$ ester-caged glutamate, Molecular Probes, Eugene, OR] was diluted in extracellular solution the day of the experiment and applied directly to the soma of the recorded cell by pressure ejection (2-10 psi). Pressure was maintained continuously during trials of exposure to UV light. Exposure to UV light in the absence of caged glutamate had no immediate effect on holding current or eEPSCs. The caged compound was diluted, and the experiments were performed with room lights dimmed or off. Microscope transillumination was turned on only to position the recording, stimulation, and pressure-ejection pipettes. Control experiments indicated that freshly diluted caged compound may have contained a low but significant level of contamination by uncaged compound. For example, application of caged glutamate at doses $>0.5 \mathrm{~mm}$ induced a small inward current and partial suppression of the eEPSC, presumably because of desensitization. Application of $\gamma$-CNB-kainate (Molecular Probes) at $>1 \mathrm{~mm}$ to a separate group of cells also induced an inward current in the dark. On the basis of the concentrations of glutamate needed to desensitize nMAG AMPA receptors and induce steady current (1-10 $\mu \mathrm{M}$; see Raman and Trussell, 1992), we estimate that contamination by glutamate was $0.1-1 \%$. Because it was necessary to use as high a dose as possible to obtain a rapid response after uncaging, even such a small percentage of contamination was problematic. The maximal dose of caged glutamate we tried that did not induce a steady current or inhibit the eEPSC in the dark was $0.5 \mathrm{~mm}$.

All values reported are mean $\pm \mathrm{SD}$, except as indicated.

\section{RESULTS}

\section{Caged glutamate experiments}

Because of the rapid kinetics of AMPA receptors, a direct measurement of receptor sensitivity of the postsynaptic cell after synaptic activity required application of glutamate within milliseconds after the eEPSC. To achieve this time resolution, we used a pressure pipette to apply bath solution with $500 \mu \mathrm{M} \gamma$-CNBglutamic acid, a chemically inactive or "caged" form of glutamate, to individual nMAG neurons in the slice (Callaway and Katz, 1993; Wieboldt et al., 1994; see Materials and Methods). Brief (10-20 msec) exposures to UV light caused photolysis of the caged glutamate, eliciting large $(1-4 \mathrm{nA}$; holding potential $=-30$ $\mathrm{mV}$ ) rapidly rising $(8 \mathrm{msec})$ currents. Figure $1 A$ shows a family of such responses evoked by 10 -msec-duration shutter openings (beginning at each inverted triangle); asterisks mark those responses preceded at differing intervals by an eEPSC (arrow). At an interval of $15 \mathrm{msec}$, eEPSCs caused a significant depression $(13 \pm 8 \% ; n=$ $11 ; p>0.005)$ of the peak current evoked by caged glutamate. However, in this type of experiment, not all receptors activated by exogenous agonist can be reached by the transmitter from one axon terminal. If the eEPSC is produced by the activity of only one of the approximately three synapses on the nMAG cell (Jackson and Parks, 1982; see Materials and Methods) and if one assumes that all AMPA receptors are subsynaptic, then the actual fraction of receptors desensitized by transmitter is approximately three times higher than the measured value, or $39 \%$. Moreover, given the likelihood that extrasynaptic receptors also are activated by the exogenously applied agonist, the level of desensitization is probably higher. As expected, if postsynaptic receptor desensitization caused the depression, the magnitude of postsynaptic depression at the shortest interval was well correlated with the size of the synaptic conductance; larger synaptic responses caused more postsynaptic depression, as shown in Figure $1 C$. Complete recovery of the peak of the uncaging response required $>50 \mathrm{msec}$ (Fig. $1 B$ ). However, the recovery time of sensitivity was difficult to measure accurately, because repeated trials of uncaging made synapses progressively weaker, despite the consistency of the postsynaptic responses of cells to uncaged glutamate. In all cases, the experiment was performed beginning with the shortest intervals between the eEPSC and the flash; a decline in the eEPSC would therefore minimize the inhibition of the uncaging responses (Fig. 1C) and seem to hasten recovery. The apparent presynaptic decline may have resulted from repeated exposure to UV light or could have been a secondary effect of the chemical byproduct of the uncaging reaction.

\section{Cross-desensitization}

This limitation was overcome by experiments that took advantage of "cross-desensitization" of AMPA receptors (Kiskin et al., 1986; Patneau and Mayer, 1991), allowing us to measure directly the recovery from desensitization by synaptically released glutamate. AMPA receptor agonists kainate and glutamate activate the AMPA receptor by binding to the same site, but only glutamate produces a strong desensitization (Kiskin et al., 1986; Patneau and Mayer, 1991; Raman and Trussell, 1992). Thus, if receptors are exposed simultaneously to both agonists, a competition results, leading to a "partially desensitized" equilibrium current intermediate between the steady-state responses to each agonist alone.

We tested whether such a competition could be observed between glutamate released from a nerve terminal and pressureapplied kainate (15-20 $\mu \mathrm{M}$ or $0.5-1 \mathrm{~mm})$. After a kainate-induced inward current achieved a steady amplitude (arrow in Fig. $2 \mathrm{~A}$; $-0.60 \pm 0.16 \mathrm{nA}$, holding potential -35 to $-40 \mathrm{mV}, n=7$ for 15-20 $\mu \mathrm{M} ;-3.00 \pm 0.92 \mathrm{nA}$, holding potential -17 to $-25 \mathrm{mV}$, $n=5$ for $0.5-1 \mathrm{~mm}$ kainate), eEPSCs were elicited. In the presence of kainate, eEPSCs showed a dose-dependent reduction in amplitude, as expected if subsynaptic receptors were occupied by kainate. For 15-20 $\mu \mathrm{M}$ kainate, the ratio of the peak amplitude of the eEPSC in kainate to that in control solutions was $0.89 \pm 16$ $(n=7)$, whereas that of $0.5-1 \mathrm{~mm}$ kainate was $0.32 \pm 18(n=5)$.

Despite their reduced size, the rapid inward-going EPSC was followed by a transient inhibition of the steady kainate-induced current. Figure $2 B$ shows this block of kainate-evoked current by subtracting the steady current level before the stimulus and superimposing the eEPSCs in control and kainate solutions. It is evident that the synaptic currents in kainate continued to decay past the prestimulus baseline current level, yielding a net outward current. Furthermore, in Figure $2 C$, larger eEPSCs produced a greater maximal block of steady-state kainate current, a result consistent with the effect of the EPSC on uncaged glutamate-evoked current in Figure $1 C$. Figure $2 C$ also shows that the degree of block was not dependent on the kainate concentration and, thus, the resting holding current, indicating that the outward current does not result from a transient loss of voltage clamp. Excluding the block after activation of the three weakest synapses shown in Figure $2 C$, the average percentage of reduction in the kainate-evoked current was $12 \pm 3 \%(n=8)$. Following the arguments given above for synapse number, this degree of block corresponds to the desensitization of at least $36 \%$ of AMPA receptors at the active synapse. The time from the onset of 

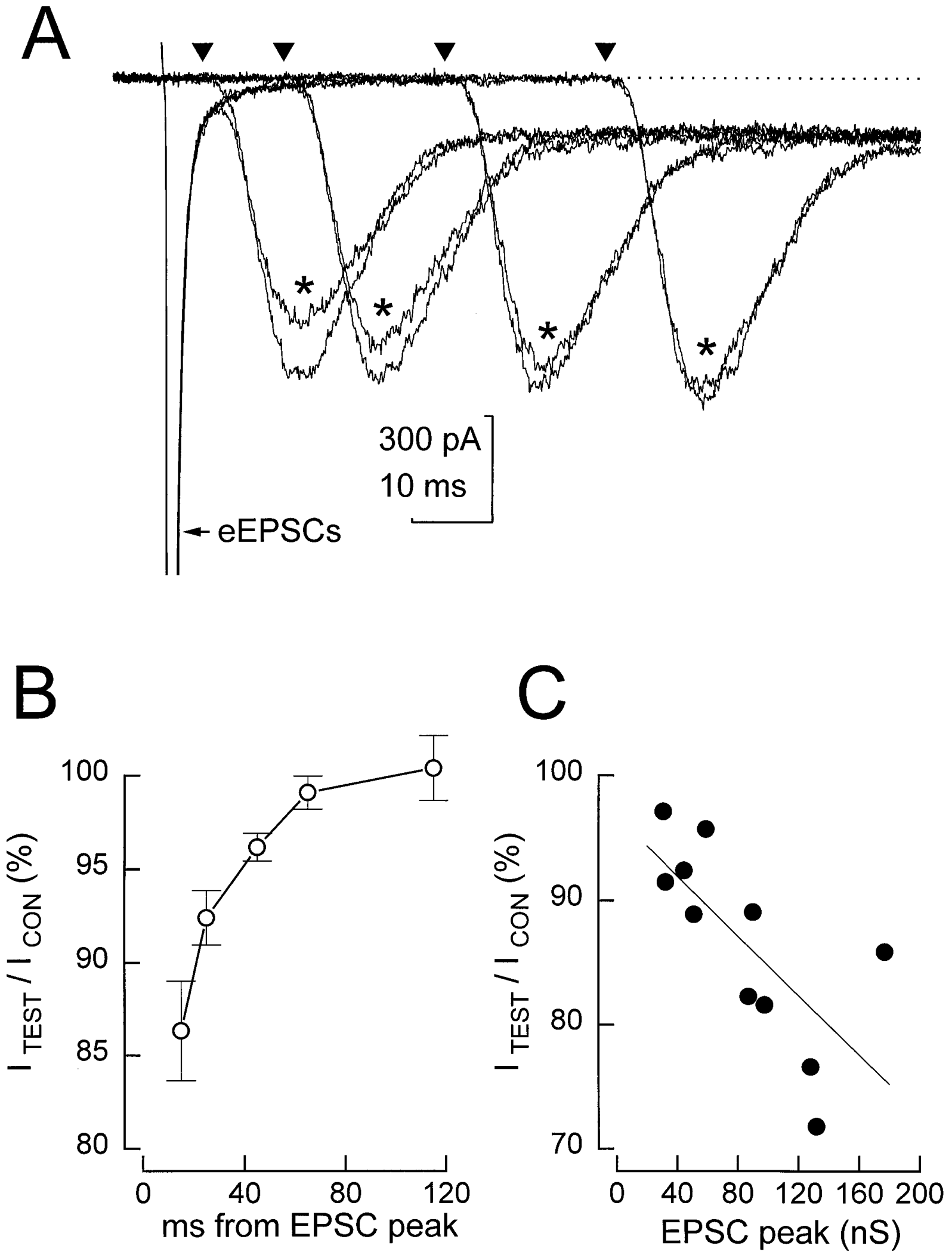

Figure 1. Synaptic AMPA receptor desensitization measured by photolysis of caged glutamate. A, A family of eight trials in response to photolysis of $500 \mu \mathrm{M} \gamma$-O-CNB glutamate with shutter openings beginning at the times marked by the inverted triangles. In four of the trials (marked by asterisks), the photolysis currents have been preceded by eEPSCs (arrow; peaks not shown). Note the recovery of depression of the peak photolysis currents as the interval between conditioning eEPSC and shutter opening is lengthened. $B$, The average inhibition of the peak photolysis current $\left(100 \times I_{\mathrm{TEST}} / I_{\mathrm{CON}}\right.$; \pm SEM) versus time after the eEPSC is plotted for 11 neurons, in which $I_{C O N}$ is the unconditioned photolysis current. $C$, Inhibition of the peak photolysis current versus the peak conductance of the conditioning synaptic current at the shortest interval (15 msec), showing that larger synaptic currents result in greater depression of the photolysis current. A linear regression $(r=-0.71)$ has been superimposed. 

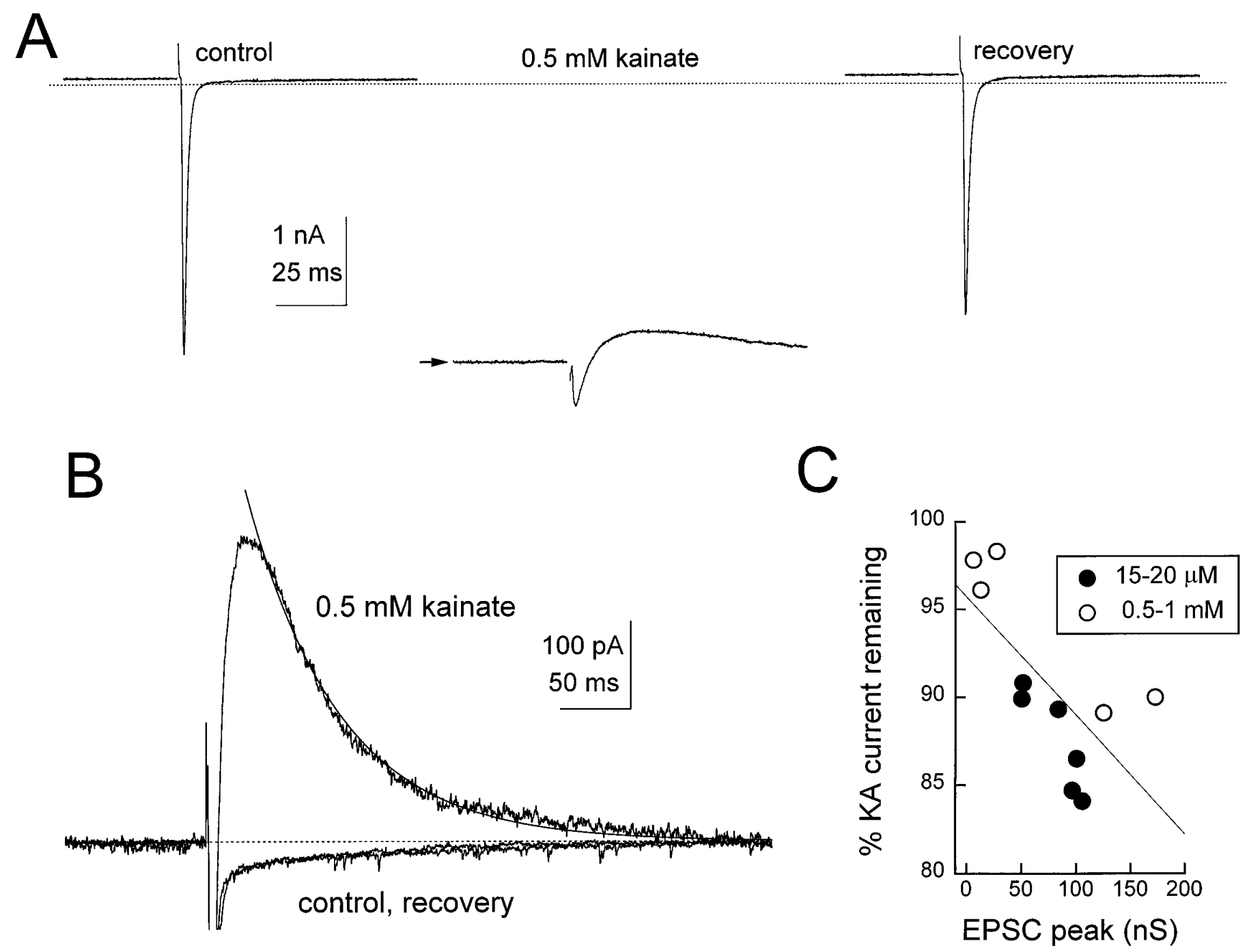

Figure 2. Synaptically released glutamate displaces kainate and desensitizes AMPA receptors. $A$, eEPSCs at a holding potential of $-17 \mathrm{mV}$ in control conditions, superimposed on a steady-state kainate current, and after recovery. Each trace is the mean of two to four responses with no leak subtraction. $B$, The same responses, filtered at $1 \mathrm{kHz}$ and with the steady-state currents subtracted, show a net positive current attributable to a block of the kainate current during the falling phase of the synaptic current. The continuous curve superimposed on the $0.5 \mathrm{~mm}$ kainate response is a single exponential with a time constant of $66 \mathrm{msec}$. $C$, The relation between the unblocked current and the magnitude of the peak control synaptic conductance in the presence of a low or high kainate concentration. The percentage of kainate current remaining was determined after baseline subtraction, as in $B$, by subtracting the record in control. The peak positive current then was divided by the steady-state kainate current to yield fractional blocked kainate current. The percentage of remaining current $=100 \times(1-$ fractional blocked current $)$. The line is a linear regression; $r=-0.7$. Dotted lines in $A$ and $B$ show the zero current level.

the EPSC to the "peak" of the outward-going current was $44 \pm 25$ msec, independent of kainate concentration. Exponential fits (thick line superimposed on kainate trace in Fig. $2 B$ ) to the recovery phase of the blocked kainate current in eight cells gave a mean time constant of $53 \pm 20 \mathrm{msec}$, independent of kainate concentration. Thus, the times for onset and offset of outward current indicate that full recovery of receptors was delayed by nearly $100 \mathrm{msec}$. These data suggest that synaptically released glutamate effectively competed with kainate, transiently desensitizing subsynaptic receptors. An alternative is that synaptic glutamate might inhibit AMPA/kainate receptors indirectly via activation of a metabotropic glutamate receptor. However, this is unlikely, because the onset of block seemed too rapid for a second messenger-mediated response and because selective activation of metabotropic glutamate receptors had no effect on the EPSC (Otis and Trussell, 1996).

\section{Depression of quantal currents}

Reduction in transmitter sensitivity may account, in part, for synaptic depression, a characteristic feature of nMAG (Zhang and Trussell, 1994a; Otis et al., 1996). According to the quantal hypothesis, such depression would be reflected in a reduction in the size of the mEPSC (Magleby and Palotta, 1981). We tested for depression of quantal size by eliciting eEPSCs in a $\mathrm{Sr}^{2+}$. containing extracellular solution, which increases the probability that single transmitter vesicles are released from the stimulated synapse for a short period after the eEPSC (Dodge et al., 1969; Goda and Stevens, 1994). To ensure that this manipulation had no pre- or postsynaptic effects that enhanced desensitization, we elicited pairs of eEPSCs to test for an effect of $\mathrm{Sr}^{2+}$ on pairedpulse synaptic depression, or PPD (amplitude of the second eEPSC/amplitude of the first eEPSC $\times 100)$. In the presence of 3 

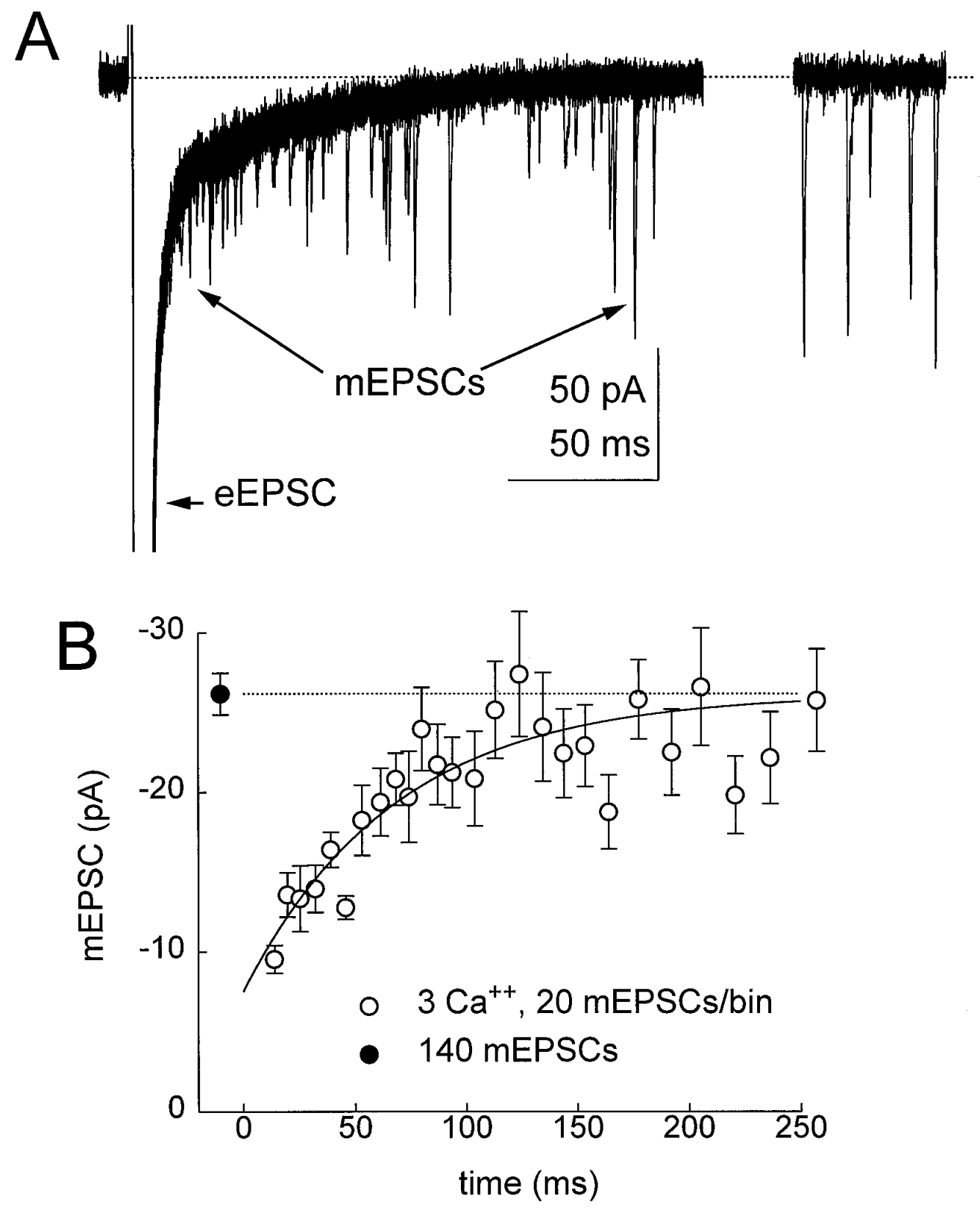

Figure 3. Quantal size is transiently reduced after a stimulus-evoked EPSC (eEPSC) only under conditions of high-release probability. $A$, Twelve eEPSCs (peaks truncated) recorded in $2 \mathrm{mM} \mathrm{SrCl} / 3 \mathrm{mM} \mathrm{CaCl}_{2}$, demonstrating a transient depression in mEPSC size. To the right, five control traces recorded before five stimuli are displayed. $B$, Mean mEPSC amplitude versus time from the initial rise in the eEPSC for the same cell. Open circles, Mean \pm SEM of 20 mEPSCs; filled circle, mean of 140 control EPSCs. The solid line is a single exponential curve with a time constant of $68 \mathrm{msec}$.

$\mathrm{mm} \mathrm{CaCl} 2, \mathrm{Sr}^{2+}$ had no significant effect on average PPD (see Fig. $5 B 1, B 2$; control, $11 \pm 8 \%, n=54$ synapses; $\left.\mathrm{Sr}^{2+} 16 \pm 8 \%, n=7\right)$, indicating that $\mathrm{Sr}^{2+}$ had no pre- or postsynaptic actions that might accentuate desensitization.

Figure $3 A$ illustrates eEPSCs and a flurry of subsequent mEPSCs after each evoked response. It is apparent that mEPSCs were reduced in amplitude immediately after each eEPSC but gradually recovered to the prestimulus amplitude over several tens of milliseconds. The depression of the postsynaptic quantal current in this same cell was quantified by measuring peak amplitudes and times of occurrence of the mEPSCs relative to the eEPSC. Figure $3 B$ shows the average mEPSC amplitude over time after the onset of the eEPSC (open circles), as well as the average mEPSC during the $2 \mathrm{sec}$ periods before the eEPSCs (filled circle). Cumulative distributions of mEPSCs were compared and tested for significant differences by the Komolgorov-Smirnov test. In each neuron, all mEPSCs within $100 \mathrm{msec}$ after each eEPSC (poststimulus mEP$\mathrm{SCs}$ ) in a given condition were compared with mEPSCs in the 2-3 sec period preceding each eEPSC (referred to as prestimulus or control mEPSCs). These comparisons showed a significant depression of the mEPSC amplitudes within the first $100 \mathrm{msec}$ after the eEPSC in seven of seven neurons $(p<0.006)$. Despite the average depression of $>46 \%$, the coefficient of variation of the mEPSC amplitude was unchanged ( $C V$ before eEPSC, $66 \pm 4 \%$; $C V$ in the first $50 \mathrm{msec}$ after the eEPSC, $60 \pm 11 \%$; $n=7$ ), arguing against the detection of a subset of events after the eEPSC via biased sampling.

If the reduction in mEPSC size resulted from a large or pro- 

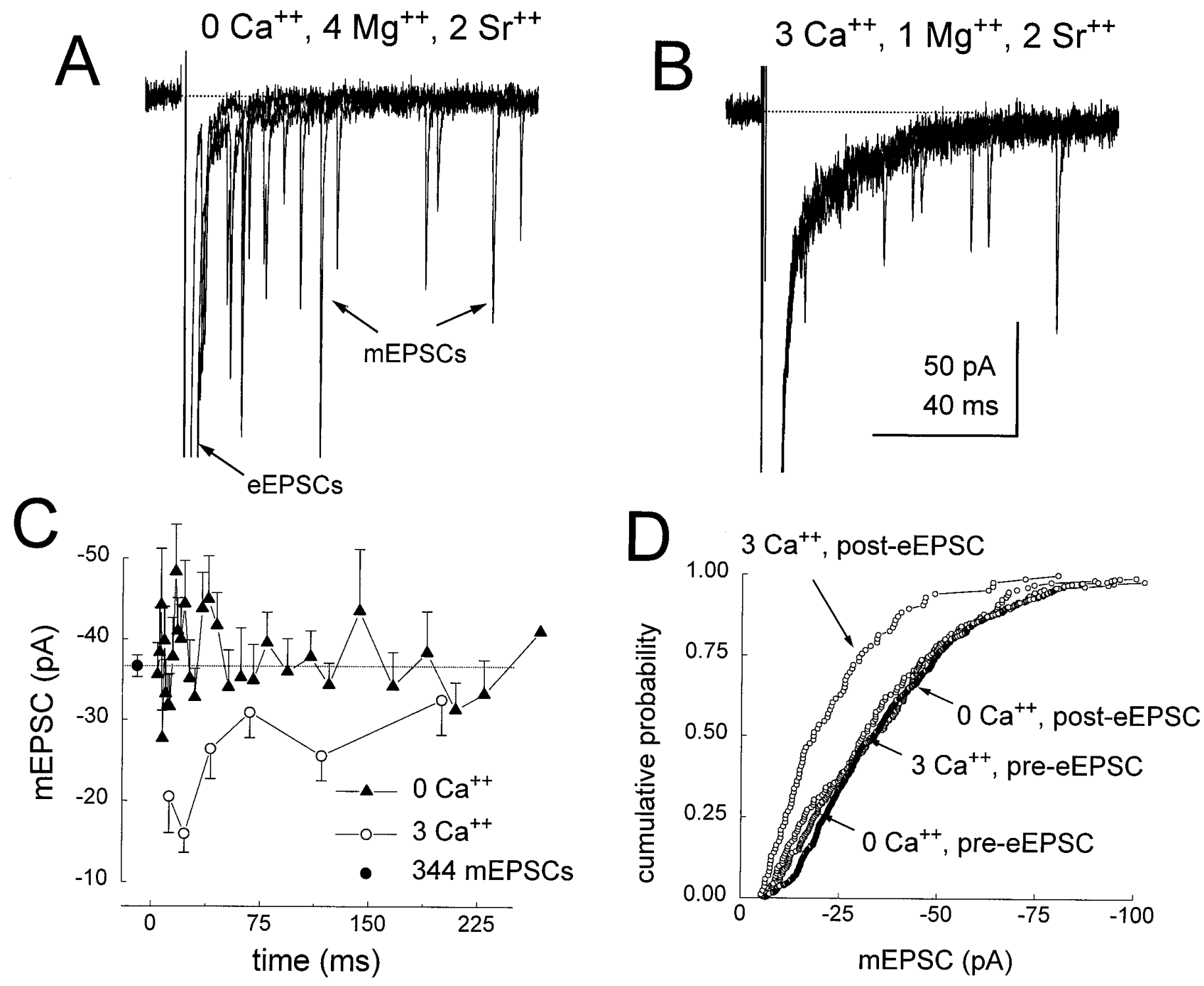

Figure 4. Quantal depression is absent when transmitter release is reduced. $A$, No depression of $\mathrm{mEPSCs}$ is seen in $2 \mathrm{~mm} \mathrm{SrCl} / 20 \mathrm{~mm} \mathrm{CaCl}{ }_{2} . B$, In the same neuron as in $A$, mEPSCs in $2 \mathrm{mM} \mathrm{SrCl}_{2} / 3 \mathrm{~mm} \mathrm{CaCl}_{2}$ show depression. $C$, Mean mEPSC amplitude $\pm \mathrm{SEM}$ versus time from initial rise of eEPSC from the same cell shown in $A$ and $B$. Filled triangles, open circles, Mean of $20 \mathrm{mEPSCs}$ in $0 \mathrm{~mm}$ or $3 \mathrm{~mm} \mathrm{Ca}^{2+}$ solutions, respectively. Filled circle, Mean of 344 control mEPSCs. D, Cumulative probability distributions of mEPSC amplitudes from the same cell demonstrate that mEPSCs within $100 \mathrm{msec}$ of an eEPSC in normal $\mathrm{Ca}^{2+}\left(3 \mathrm{Ca}^{2+}\right.$, poststimulus $)$ are significantly depressed as compared with events after an eEPSC in $0 \mathrm{Ca}^{2+}\left(0 \mathrm{Ca}^{2+}\right.$, poststimulus $)$, or preceding eEPSCs in $0 \mathrm{Ca}^{2+}\left(0 \mathrm{Ca}^{2+}\right.$, prestimulus $)$ or $3 \mathrm{Ca}^{2+}\left(3 \mathrm{Ca}^{2+}\right.$, prestimulus; Komolgorov-Smirnov test, $p<0.0005)$. Calibration bar in $B$ applies also to $A$.

longed exposure to transmitter, depression of the mEPSC would be expected to be lessened when release probability was reduced, as is PPD (Otis et al., 1996). eEPSC and mEPSC measurements were repeated in solutions with $\mathrm{MgCl}_{2}$ substituted for $\mathrm{CaCl}_{2}$, which reduced the eEPSC by $86 \pm 7 \%(n=4)$ and eliminated synaptic depression, instead supporting a slight facilitation of the eEPSC at a $10 \mathrm{msec}$ interval (PPD of $105 \pm 43 \%$; $n=4$ ). The transient reduction in quantal size was not seen under conditions of low release probability; quantal size was invariant after the eEPSCs in four of four cells $(p>0.3$ by Komolgorov-Smirnov test; Fig. $4 A-D$ ). This finding confirms that high levels of release are required to depress mEPSCs. It is apparent from Figure $4 A, B$ that the frequency of mEPSCs was higher in zero $\mathrm{Ca}^{2+}$. Although this may reflect reduced detectability of mEPSCs in $\mathrm{Ca}^{2+}$ solu- tions, it more probably indicates an antagonism between $\mathrm{Ca}^{2+}$ and $\mathrm{Sr}^{2+}$ in inducing mEPSCs after the eEPSC.

The depression in mEPSC mean amplitude is most likely attributable to the receptor desensitization shown in Figures 1 and 2, although in mEPSC experiments it is difficult to rule out other presynaptic factors dependent on high release probability, such as the selective release of partially filled vesicles. However, if postsynaptic receptor desensitization causes part of the depression, then the restoration of mEPSC amplitude after the eEPSC should indicate the rate at which subsynaptic AMPA receptors become available after glutamate clearance and recovery from desensitization. In six of seven neurons, a single exponential described the time course of recovery of mean mEPSC amplitude up to the prestimulus mean amplitude (see continuous curve in 


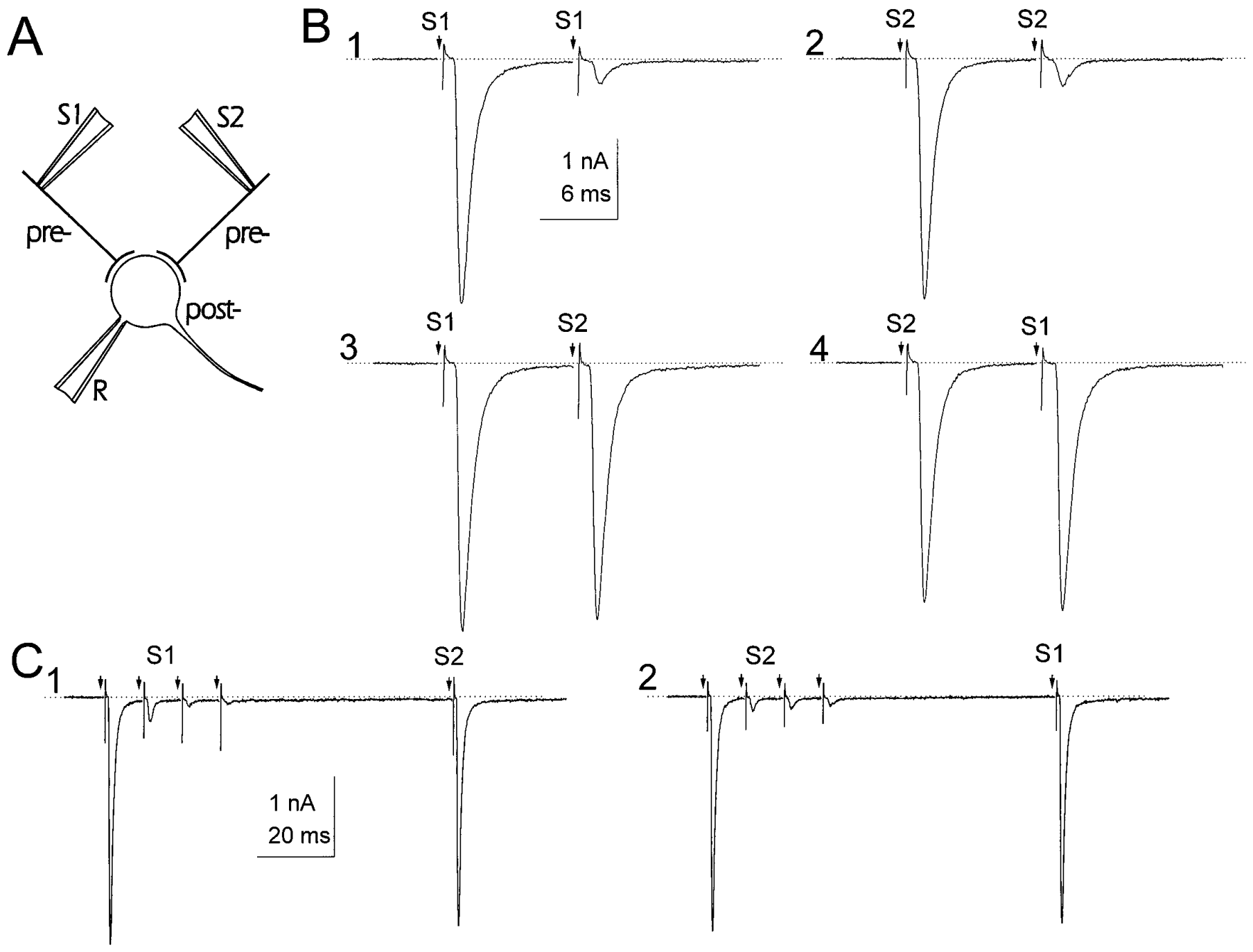

Figure 5. Synaptic depression is synapse-specific. A, Schematic showing the whole-cell recording pipette and two extracellular stimulating pipettes (S1, $S 2$ ), each with an isolated ground. $R$ is the recording pipette. B1, B2, Pairs of stimuli delivered to either of the two stimulating pipettes elicit strong depression. B3, B4, By contrast, stimulation with one, followed $10 \mathrm{msec}$ later by the other, extracellular pipette evokes eEPSCs with no depression. $C$, Conditioning trains of stimuli (4 at $100 \mathrm{~Hz}$ ) elicit strong homosynaptic depression, but no heterosynaptic depression.

Fig. $3 B$ ), giving a mean time constant of $106 \pm 85 \mathrm{msec}$ and a peak mEPSC depression at $5 \mathrm{msec}$ of $47 \%$. These values are consistent with the estimates of the extent of depression measured with caged glutamate and exogenous kainate and with the rate of recovery in kainate described above.

\section{Absence of interactions between axon terminals}

Our experiments show that synaptically released glutamate desensitizes AMPA receptors at a single calyceal synapse. Because approximately three auditory nerve axons form synapses on the cell body of each nMAG neuron (Jackson and Parks, 1992), it was of interest to test whether glutamate released from one terminal might diffuse to and desensitize receptors under a neighboring calyceal contact on the same neuron. A recording configuration with which the activity of two converging inputs can be monitored is schematized in Figure $5 \mathrm{~A}$. Individual nMAG neurons were voltage-clamped with a whole-cell recording pipette $(R)$, while separate auditory nerve inputs to the same cell were activated at different times (denoted by arrows and either $S 1$ or $S 2$ in Fig. $5 A-C$ ). As under control conditions with a single stimulating pipette, pairs of stimuli delivered to the same pipette separated by an interval of $10 \mathrm{msec}$ elicited PPD (Fig.
$5 B 1, B 2$; mean, $12 \pm 2 \% ; n=6$ synapses from 4 cells). By contrast, Figure 5, $B 3$ and $B 4$, illustrates that stimuli delivered to one pipette and then to the other at a $10 \mathrm{msec}$ interval elicited eEPSCs with no depression (mean, $102 \pm 13 \% ; n=4$ cells). As shown in Figure $5 C$, even strong activation by repetitive stimulation of one synapse could not induce heterosynaptic depression (mean: $100 \pm 11 \% ; n=3$ cells).

\section{DISCUSSION}

Previous work has suggested that desensitization may contribute to the decay of single EPSCs and regulate the size of the EPSC during repetitive firing (Trussell et al., 1988, 1993; Tang et al., 1989; Barbour et al., 1994; Takahashi et al., 1995; Otis et al., 1996). Provided that most receptors are bound, some postsynaptic depression is expected, as even the briefest exposures to glutamate induce partial desensitization, which recovers at a rate intrinsic to the receptors (Colquhoun et al., 1992; Hestrin, 1992; Raman and Trussell, 1995). In this report, we have measured directly the magnitude and duration of postsynaptic depression resulting from desensitization. The time constant of recovery from synaptic desensitization was stated previously to be 
identical to the intrinsic recovery time of AMPA receptors (Trussell et al., 1993). However, in that study, membrane patches and synapses were not studied at the same temperature, and although robust synaptic depression was seen at higher temperatures, quantitative comparison of the rates of recovery is problematic. The studies of Raman and Trussell (1995), Otis et al. (1996), and the present work were all performed at room temperature. Taken together, these studies indicate that the recovery of receptor sensitivity depends on factors in addition to the time for recovery from desensitization intrinsic to the AMPA receptor (16 msec exponential time constant; Raman and Trussell, 1995). These factors include the quantal content as well as the time course of transmitter clearance, previously shown to depend on transmitter uptake (Otis et al., 1996). Simulations of diffusion suggest that micromolar levels of transmitter might persist for at least several milliseconds in synapses of diverse morphology (Barbour et al., 1994; Holmes, 1995; Clements, 1996; Otis et al., 1996; Wahl et al., 1996). Such transmitter concentrations, although not sufficient to activate AMPA receptors strongly, would delay recovery from desensitization. As the onset and recovery rates for desensitization seem to be regulated by differential gene expression, nuclear RNA editing, and alternative splicing mechanisms (Lomeli et al., 1994; Geiger et al., 1995), it is possible that desensitization is a regulated and synapse-specific form of short-term depression at noncalyceal synapses throughout the CNS. At sparse single-bouton synapses with rapid transmitter clearance, the lifetime of desensitization would be shortest, dependent primarily on receptor kinetics and glutamate unbinding. By contrast, postsynaptic depression would be longest at synapses with delayed glutamate clearance.

A late phase of glutamate clearance described above is evident as a small residual current at the end of the fast major component of the EPSC (Otis et al., 1996). The present work indicates that at least some of this current must reflect equilibrium between open and desensitized receptors. Indeed, the high level of desensitization we observed suggests that a majority of receptors bind glutamate during the EPSC. In the presence of kainate, the equilibration between receptors and gradually falling levels of transmitter would be expected to be slowed by the binding and unbinding of glutamate and kainate (Patneau and Mayer, 1991), presumably generating the delay to peak block of the kainateevoked current by the EPSC. In the quantal depression experiments, the mEPSCs "rode" atop the slow phase of the eEPSC, growing in amplitude as the slow eEPSC decreased. The apparent depression of the mEPSC amplitude does not simply reflect a preponderance of available receptors already being in the open state during the small, slow current ( $<2 \%$ of the peak eEPSC), because this current is generated by only a minor fraction of receptors at each release site. Rather, the parallel changes in mEPSCs and slow eEPSC reflect the gradual clearance of glutamate and reversal of desensitization.

It is of interest to determine the relative contribution of pre- and postsynaptic factors to synaptic depression. The extent of PPD may be approximated by the ratio of the quantal contents of the second and first eEPSC $\left(Q C_{2} / Q C_{1}\right)$ times the ratio of their single quantal currents $\left(V_{2} / V_{1}\right)$, the latter including desensitization. Thus, if PPD is between 0.1 and 0.2 , typical values from these studies, and $V_{2} / V_{1}$ is 0.4 , approximately the degree of synaptic desensitization we measured here, then $Q C_{2} / Q C_{1}$ would be $0.25-0.5$. This confirms previous fluctuation analysis (Trussell et al., 1993; Zhang and Trussell, 1994a) indicating that a significant drop in transmitter release parallels the reduction in glutamate sensitivity. Our estimation is confirmed by reexamination of the data in Figure 3 of Trussell et al. (1993), in which PPD was determined with (0.4) and without (0.14) cyclothiazide, a blocker of desensitization. If PPD with cyclothiazide estimates only the presynaptic component $\left(Q C_{2} / Q C_{1}\right)$ and if we assume no presynaptic action of cyclothiazide, the above reasoning gives a $V_{2} / V_{1}$ of 0.35 , similar to the more direct estimate of $35-40 \%$ from the present study. However, these values are likely to hold only for a particular set of experimental conditions. The balance between preand postsynaptic depression will depend on the rate and duration of synaptic activity. For example, release will fall during a train of stimuli, and so the contribution of desensitization to depression, which is most pronounced with a larger quantal content (Figs. $1 C$, $2 C$ ), would diminish.

Transmitter cross talk between release sites has been suggested to slow transmitter clearance and augment AMPA receptor desensitization (Trussell et al., 1993; Otis and Trussell, 1996; Otis et al., 1996). However, because neighboring calyces behave independently, this study demonstrates that transmitter desensitizes only those AMPA receptors immediately under the active terminal. The functional isolation of nerve terminals might result from uptake mechanisms located in intervening glial processes. It also may be that structural elements limit the mixture of transmitter pools released by neighboring synapses. For example, periodic widenings of the synaptic cleft between release sites in calyceal terminals (Parks, 1981) potentially could dilute transmitter before it reaches the edge of the cleft.

The calyceal terminal is a highly specialized adaptation. It is of interest, therefore, that nMAG is part of a brainstem circuit that encodes interaural time differences with a precision of tens of microseconds (Konishi et al., 1989). The role of the system in encoding time delays implies that postsynaptic nMAG spikes occur in a narrow time window after nerve terminal excitation, i.e., with little error, although it does not imply that every synaptic stimulus must result in a spike. What unique aspects of the synapse aid this performance? The massive terminal, activating AMPA receptors located electrotonically close to the axon hillock, generates a large eEPSC upon low frequency stimulation, which enables the postsynaptic cell to reach spike threshold with minimal delay jitter from trial to trial (Zhang and Trussell, 1994b). It is instructive, however, to consider complimentary adaptive features that result from calyceal morphology and the delay in transmitter clearance. For example, the slow phase of the EPSC caused by delayed clearance (Otis et al., 1996) results in a slow EPSP that, in turn, produces a plateau potential during repetitive activity (Zhang and Trussell, 1994b). This plateau potential itself does not lead to repetitive firing; rather, its role is most likely to reduce membrane time constant by activating a steady potassium conductance (Reyes et al., 1994; Zhang and Trussell, 1994b). In this way, rapid phases of subsequent EPSPs are speeded by the action of the slow EPSP component, thereby reducing temporal summation and improving transmission of timing information.

Given these adaptations to facilitate auditory transmission, it seems ironic that another consequence of the delayed transmitter clearance is postsynaptic depression. Indeed, because nMAG and other auditory neurons probably are activated at relatively high frequency in vivo, such depression must occur routinely. Why desensitize postsynaptic receptors and depress the EPSP in a region that apparently performs a precise relay function? In the chick nMAG, the rapid kinetics of AMPA receptors is paralleled by a high calcium permeability through their associated ion channel, indicating that auditory activity results in calcium loading of postsynaptic cells (Otis et al., 1995). In this regard, desensitization after transmitter release may serve to limit postsynaptic calcium influx during chronic auditory 
activity, preventing cell death associated with excessive calcium loading of nMAG neurons (Zirpel et al., 1995).

An electrical consequence of such depression may be to emphasize information in the onset of an acoustic stimulus. Accordingly, psychoacoustic studies indicate that localization of a pure tone is poorer when the onset of the tone is weakened (Hartmann, 1983). Although this result may be related to reduction of broadband spectral information contained in the onset, it also may reflect synaptic accommodation within the lower auditory pathway. In this context, it may be that, after depression, timing information is preserved via a different synaptic mechanism and to a reduced degree. After the onset of depression during presentation of a pure tone, localization may become dependent not on a large secure EPSP but, rather, on the precise temporal convergence of subthreshold EPSPs produced by multiple synapses. Indeed, as proposed by Joris et al. (1994), with such a mechanism, weakened synapses may transmit effectively with minimal jitter in timing.

\section{REFERENCES}

Barbour B, Keller BU, Llano I, Marty A (1994) Prolonged presence of glutamate during excitatory synaptic transmission to cerebellar Purkinje cells. Neuron 12:1331-1343.

Callaway EM, Katz LC (1993) Photostimulation using caged glutamate reveals functional circuitry in living brain slices. Proc Natl Acad Sci USA 90:7661-7665.

Clements J (1996) Transmitter time course in the synaptic cleft: its role in central synaptic function. Trends Neurosci 19:163-171.

Colquhoun D, Jonas P, Sakmann B (1992) Action of brief pulses of glutamate on AMPA/kainate receptors in patches from different neurones of rat hippocampal slices. J Physiol (Lond) 458:261-287.

Diamond JS, Jahr CE (1995) Asynchronous release of synaptic vesicles determines the time course of the AMPA receptor-mediated EPSC. Neuron 15:1097-1107.

Dodge FA, Miledi R, Rahamimoff R (1969) Strontium and quantal release of transmitter at the neuromuscular junction. J Physiol (Lond) 200:267-283.

Dudel J, Franke C, Hatt H, Ramsey RL, Usherwood P (1988) Rapid activation and desensitization by glutamate of excitatory, cationselective channels in locust muscle. Neurosci Lett 88:33-38.

Geiger JRP, Melcher T, Koh DS, Sakmann B, Seeburg PH, Jonas P, Monyer H (1995) Relative abundance of subunit mRNAs determines gating and $\mathrm{Ca}^{2+}$ permeability of AMPA receptors in principal cells and interneurons in rat CNS. Neuron 15:193-204.

Goda Y, Stevens CF (1994) Two components of transmitter release at a central synapse. Proc Natl Acad Sci USA 91:12942-12946.

Hartmann WM (1983) Localization of sound in rooms. J Acoust Soc Am 74:1380-1391.

Hestrin S (1992) Activation and desensitization of glutamate-activated channels mediating fast excitatory synaptic currents in the visual cortex. Neuron 9:991-999.

Holmes WR (1995) Modeling the effect of glutamate diffusion and uptake on NMDA and non-NMDA receptor saturation. Biophys J 69:1734-1747.

Isaacson JS, Nicoll RA (1991) Aniracetam reduces glutamate receptor desensitization and slows the decay of fast excitatory synaptic currents in the hippocampus. Proc Natl Acad Sci USA 88:10936-10940.

Jackson H, Parks TN (1982) Functional synapse elimination in the developing avian cochlear nucleus with simultaneous reduction on cochlear nerve axon branching. J Neurosci 2:1736-1743.

Joris PX, Carney LH, Smith PH, Yin TCT (1994) Enhancement of neural synchronization in the anteroventral cochlear nucleus. I. Responses to tones at the characteristic frequency. J Neurophysiol 71:1022-1036.

Kiskin NI, Krishtal OA, Tsyndrenko AY (1986) Excitatory amino acid receptors in hippocampal neurons: kainate fails to desensitize them. Neurosci Lett 63:225-230.

Konishi M, Takahashi TT, Wagner H, Sullivan WE, Carr CE (1989) Neurophysiological and anatomical substrates of sound localization in the owl. In: Auditory function and neurobiological bases of hearing (Edelman GM, Gall WE, Cowan WM, eds), pp 721-746. New York: Wiley.

Livsey CT, Costa E, Vicini S (1993) Glutamate-activated currents in outside-out patches from spiny versus aspiny hilar neurons of rat hippocampal slices. J Neurosci 13:5324-5333.
Lomeli H, Mosbacher R, Melcher T, Hoger T, Geiger JRP, Kuner T, Monyer H, Higuchi M, Bach A, Seeberg PH (1994) Control of kinetic properties of AMPA receptor channels by nuclear RNA editing. Science 266:1709-1713.

Magleby KL, Palotta BS (1981) A study of desensitization of acetylcholine receptors using nerve-released transmitter in the frog. J Physiol (Lond) 316:225-250.

Otis TS, Trussell LO (1996) Inhibition of transmitter release shortens the duration of the excitatory synaptic current at a calyceal synapse. J Neurophysiol 76:3584-3588.

Otis TS, Raman IM, Trussell LO (1995) AMPA receptors with high $\mathrm{Ca}^{2+}$ permeability mediate synaptic transmission in the auditory pathway. J Physiol (Lond) 482:309-315.

Otis TS, Wu YC, Trussell LO (1996) Delayed clearance of transmitter and the role of glutamate uptake at synapses with multiple release sites. J Neurosci 16:1633-1643.

Parks TN (1981) Morphology of axosomatic endings in an avian cochlear nucleus: nucleus magnocellularis of the chicken. J Comp Neurol 203:425-440.

Patneau DK, Mayer ML (1991) Kinetic analysis of interactions between kainate and AMPA: evidence for activation of a single receptor in mouse neurons hippocampal neurons. Neuron 6:785-798.

Patneau DK, Vyklicky Jr L, Mayer ML (1993) Hippocampal neurons exhibit cyclothiazide-sensitive rapidly desensitizing responses to kainate. J Neurosci 13:3496-3509.

Raman IM, Trussell LO (1992) The kinetics of the response to glutamate and kainate in neurons of the avian cochlear nucleus. Neuron 9:173-186.

Raman IM, Trussell LO (1995) The mechanism of AMPA receptor desensitization after removal of glutamate. Biophys J 68:137-146.

Reyes AD, Rubel EW, Spain WJ (1994) Membrane properties underlying the firing of neurons in the avian cochlear nucleus. J Neurosci 14:53525364.

Takahashi M, Kovalchuk Y, Attwell D (1995) Pre- and postsynaptic determinants of EPSC waveform at cerebellar climbing fiber and parallel fiber to Purkinje cell synapses. J Neurosci 15:5693-5702.

Tang C-M, Dichter M, Morad M (1989) Quisqualate activates a rapidly inactivating high conductance ionic channel in hippocampal neurons. Science 243:1474-1477.

Tang C-M, Shi Q-Y, Katchman A, Lynch G (1991) Modulation of the time course of fast EPSCs and glutamate channel kinetics by aniracetam. Science 254:288-290.

Trussell LO, Fischbach GD (1989) Glutamate receptor desensitization and its role in synaptic transmission. Neuron 3:209-218.

Trussell LO, Thio L-L, Zorumski CZ, Fischbach GD (1988) Rapid desensitization of glutamate receptors in vertebrate central neurons. Proc Natl Acad Sci USA 85:2834-2838.

Trussell LO, Zhang S, Raman IM (1993) Desensitization of AMPA receptors upon multi-quantal neurotransmitter release. Neuron 10:1185-1196.

Vyklicky Jr L, Patneau DK, Mayer ML (1991) Modulation of excitatory synaptic transmission by drugs that reduce desensitization at AMPA/ kainate receptors. Neuron 7:971-984.

Wahl LM, Pouzat C, Stratford KJ (1996) Monte Carlo simulation of fast excitatory synaptic transmission at a hippocampal synapse. J Neurophysiol 75:597-608.

Wieboldt R, Gee KR, Niu L, Ramesh D, Carpenter BK, Hess GP (1994) Photolabile precursors of glutamate: synthesis, photochemical properties, and activation of glutamate receptors on a microsecond time scale. Proc Natl Acad Sci USA 91:8752-8756.

Yamada KA, Tang C-M (1993) Benzothiadiazides inhibit rapid glutamate receptor desensitization and enhance glutamatergic synaptic currents. J Neurosci 13:3904-3915.

Zhang S, Trussell LO (1994a) Voltage-clamp analysis of excitatory synaptic transmission in the avian nucleus magnocellularis. J Physiol (Lond) 480:123-136.

Zhang S, Trussell LO (1994b) A characterization of excitatory postsynaptic potentials in the avian nucleus magnocellularis. J Neurophysiol 72:705-718.

Zhou N, Parks TN (1992) Developmental changes in the effects of drugs acting at NMDA or non-NMDA receptors on synaptic transmission in the chick cochlear nucleus (nuc. magnocellularis). Dev Brain Res 67:145-152.

Zirpel L, Lachica EA, Lippe W (1995) Deafferentiation increases the intracellular calcium of cochlear nucleus neurons in the embryonic chick. J Neurophysiol 74:1355-1357. 